\title{
1. Overview: visual branding in historical perspective
}

When did advertising begin? This question distracts rather than enlightens. The rhetorician doesn't care. ${ }^{1}$

A better question is: by what point had magazine advertising for national brands fully emerged in the United States? ${ }^{2}$ As rhetoricians, we are not interested in the dawn or even the sunrise, but the entire day, beginning in the morning, the earliest hour which enjoys the full light of day. For brand advertising, complete with visual branding, that point lies somewhere around the turn of the twentieth century. The sky was beginning to redden in the 1870s: Ivory Soap and other pioneer brands had been introduced, the American continent was being knit together into a national market, and printing technology and media custom were beginning to facilitate illustrations in advertising. ${ }^{3}$ Sunrise, to continue the metaphor, can be securely dated to 1892-93. This period marked the launch of the low-priced, mass-circulation magazine whose revenue depended more on advertising dollars than subscription payments. ${ }^{4}$ This is also the period when the better magazines began to refuse patent medicine ads; in other words, the point where ads could not all be dismissed as bunkum. By 1905, brands and trademarks had received major new legal protections. ${ }^{5}$ The sun had moved completely above the horizon.

By the early years of the twentieth century, color printing in mass reproduction had been feasible for some years, although it was still uncommon in print advertisements. Mass circulation magazines like the Ladies Home Journal (LHJ) had flourished for over a decade, pulling in more than 1 million subscribers. Nationally distributed brands had proliferated since their advent after the Civil War. By 1900 the American economy, after devastating slumps that began in the early 1870 s and continued through the middle 1890s, was booming again. The large corporation, promoting its brand to a national audience of millions, was in place. ${ }^{6}$

A remark sometimes attributed to Albert Einstein asserts that "everything should be made as simple as possible, but not simpler." Advertising from around the turn of the twentieth century is early enough to anchor a history of visual branding in advertising, and we need nothing earlier to establish trends. Hence, this will be history over 12 decades, from about 1893 to 2015. For brevity, we will call it a century. 


\section{HISTORICAL COMPARISONS}

Although magazine advertising was fully formed by the early twentieth century, along with the mass-marketing of national brands, other innovations were yet to come. Many products, heavily advertised in later decades, had not as yet become mass-marketed goods: the automobile, for instance, is nearly absent from magazine ads in the early 1900s, but common in 1920 s ads. Conversely, some product categories which were heavily advertised in the early years of the 1900s - corsets, for instance - are no longer mass-market goods.

From the standpoint of identifying change in rhetorical practices, if we were to compare a 2015 ad for cell phones, with a 1905 ad for corsets, we would have two variables in one equation. We could not solve for rhetorical practices that were specific to 1905 , separate from practices that were specific to advertising corsets during the Edwardian era of dress and fashion. Historical differences would be confounded with product category differences. To keep the focus on how visual branding changed over the century, it helps if we constrain the set of products. Fortunately, many categories were heavily advertised throughout the period. These include: (1) packaged foods; (2) personal care products, from soap to toothpaste; (3) household cleaning products (for example, scouring powder); and (4) home furnishings and improvements, such as flooring, furniture, cabinetry, paint, and appliances.

We could obtain an even tighter comparison if we constrained brand as well as product. Many of the most famous brands, treated by historians as central players in the development of consumer culture, were already flourishing by early in the twentieth century: Campbell's, Heinz, Ivory, Jello. When we place a Campbell's soup ad from 1905 beside another from 2015, we hold both product category and brand constant. By imposing such constraints, differences over time in rhetorical practice more clearly emerge. Unfortunately, the turnover in brands across a period this lengthy made it impossible for us to fully observe this second guideline. ${ }^{7}$

Constraining brand, where possible, yields a second benefit. Do you remember Huyler's or Lowney's chocolates? Probably not; but at the beginning of the period, these vied with Hershey's as leading brands of chocolate. Ultimately these other brands disappeared or were reduced to minor status, and did not continue as leaders. Did bad advertising wreck the Huyler brand franchise? There is no way to tell. But if good advertising contributes to successful branding - an uncontroversial proposition - then the incidence of bad advertising, in the population of failed brands, must be higher than in the population of brands that have enjoyed long-term success. Hence, were we to compare a 1900 Huyler's chocolate ad to a 2015 Hershey's ad, we would risk comparing ignorant or mistaken rhetorical 
practice to effective and sound practice, and lose sight of the comparison on which we seek to focus, which is early versus later practice.

Rhetoricians haven't time to catalogue or collect. Rhetoricians are not antiquarians. Rhetoricians care only about what works. Plato condemned us for it. As a rule, we will try to avoid reproducing old ads for vanished product categories or for brands that have disappeared or dwindled into insignificance. We did look at these ads, and when we categorize the ads from a period, our global assessments will include them. But for the examples we reproduce, we strive to set a higher bar. On the other hand, it will not do to altogether exclude new brands in new product categories. These may introduce new rhetorical possibilities. We reiterate the fundamental assumption of classical rhetoric: in any rhetorical situation, the number of gambits - potentially successful moves in the game - is finite and even small. But new products may introduce a new persuasive situation, with newly possible gambits. We may skimp on vanished products and brands, but we cannot dismiss new products and new brands, if we are to grasp the full panoply of rhetorical practices in visual branding, and their trajectory over time.

\section{PREREQUISITES FOR BRAND ADVERTISING}

There is another reason to start a rhetorical history of brand advertising in the 1890s. Prior to the 1880s, the professions of copywriter and art director did not exist. There was plenty of print advertising before that point, but it was not produced by specialists. Numerous ad agencies predate 1890 , but they primarily sold space in publications, placing material created by the advertiser. $^{8}$ The owners of firms, or one of their clerks, constructed those print ads. Copy was minimal, and visual elements were selected rather than constructed: type foundries offered an abundance of display typefaces and simple graphics. ${ }^{9}$ If the business owner had some flair, as did Harley Procter of Procter \& Gamble ("99 44/100\% pure," "It floats"), ad copy might be creative, and stylistically astute; else, it tended toward boilerplate puffery, stiff announcements, or the shouts of the barker, with graphic support limited to canned elements. ${ }^{10}$

It was after 1890 that more and more of the ads appearing in the new magazines began to be written by specialists. ${ }^{11}$ Art directors, who constructed the visual appearance of the ad, came later. ${ }^{12}$ Before 1900 , many ads changed no more frequently than packaging changes today. The same graphics and selling copy would be run again and again, for years. Only as the century turns do we see more and more ad campaigns take the form of ever-changing executions: newly written copy supported by newly 
constructed illustrations, ads made from scratch. Only from this point do we see professionals take charge of ad design. Professional rhetoricians begin to make a living from advertising.

Before 1898, new products had been introduced at a quickening pace for several decades. These new products always had names, and like Ivory or Quaker Oats, some of these names survived and thrived as brands. But it was only with the introduction of Nabisco crackers in that year that a business owner, head of the new cracker combine, tapped an ad agency and its staff of specialists to design a new name for a product that had already been manufactured and mass-distributed for years. Uneeda Biscuit may have been the first new brand to be launched, separate from the launch of the product it named. ${ }^{13}$

Last, why put so much weight on magazine advertising, when the topic is the broader one of visual branding in advertising? Here it helps to introduce a distinction with another form of advertising, one familiar to marketing scholars, but one that may pass over the heads of historians not trained in the business disciplines. Most advertising prior to the advent of advertising-supported magazines was direct response advertising: its purpose was to get the consumer to reach for her purse and buy, right now, as in direct mail advertising today. It is no accident that John Powers, widely recognized to be the first professional copywriter, came into his own while working for a department store, writing ads to be read in a daily newspaper, aimed at consumers about to go shopping.

Early magazine advertising, through the first years of the twentieth century, was sometimes designed as direct response advertising; but from the beginning, and increasingly, it advertised the brand, not the sale. Magazine ads, above all, built the brand in the eyes of those who might buy, not immediately but in the near future; and also those who had bought and sought reassurance; and even those who might, some years later, consider buying. Brand advertising builds brands; other forms of marketing sell the product thus branded. ${ }^{14}$ Advertising, and brands, and magazines all predate the 1890s; nonetheless, the 1890s provide a defensible point of beginning for a sample designed to capture trends in visual branding over the long term, down to the present day.

\section{CAPSULE SUMMARY: A CENTURY OF BRANDING IN PRINT}

Before pursuing detailed comparisons using example ads, here is a broad brush picture of developments over time. In this account we periodically jump ahead 25 to 30 years (see Box 1.1 for details of the sampling strategy). 


\section{BOX 1.1 A PUNCTUATED INTERVAL SAMPLING STRATEGY}

We stress again the importance, for historical studies of visual branding, of holding in the hand the physical magazine. True, in an age of digital archiving, it is increasingly possible to find old magazines digitized on the Internet; and the new archiving has largely avoided the foibles of past archivists, at whom Rowsome (1959, p. 1) railed: "[shame on] the nameless past librarians who in years gone by instructed the bindery to cut off and discard advertising sections before binding magazine volumes."

What you can't descry from an internet scan of an old ad is the exact caliber of the printing process, nor even the size of the original ad: about 6.5 inches by 9.5 inches for a Munsey's, McClure's or Cosmopolitan, but over 11 inches by 16 inches for a Ladies Home Journal or a Saturday Evening Post; a page almost three times as large. Few subsequent authors have been as scrupulous as Presbrey (1929), who noted the degree of photo enlargement or reduction for most of his reproductions. As a consequence, the modern reader may see what looks like a half-page ad reproduced in a book or digital archive, and not realize that the original was as small as a classified newspaper ad; or you may see a large and highly detailed ad and not be told that this ad appeared on the back cover, and was the only full-page ad in the entire magazine.

However, the imperative for obtaining physical copies, combined with their absence from many modern libraries, creates a dilemma: although it is easy to find old magazines for sale by searching the web, once you go back a century these may cost as much as $\$ 50$ per issue. The initial impetus for our punctuated sample was this prohibitive cost. Rather than the rigorously specified date sampling of a Pollay (1985), we decided it would be acceptable to buy a 1907 issue, and assign it to the "around 1900" sample, because that issue had a nick on the cover and was available for half the price of any issue from the year 1900 .

What makes this haphazard selection viable are the gaps in time we imposed: jumping ahead to buy a copy from 1921, and again to get a copy from 1954, using the same cost-minimization rule. Each loosely bounded in time sample serves as an instrument for clarifying what's different about the preceding and following sample. The length of the gap - two or three decades - improves the resolution. When we juxtapose two ads produced decades apart, the differences leap out. And with five punctuated samples, we had four opportunities to make that juxtaposition; which in turn made sustained trends easy to spot.

You don't have to obtain physical copies of old magazines to pore over examples of old ads. Most of the histories we consulted reproduce ads in copious quantities. But in addition to not capturing size information, reproduced ads tend not to be time-locked. Rather, the typical volume takes a thematic approach: here a chapter on breakfast food ads that might span one 20-year stretch, there a chapter on early automobile ads that might span a different 30-year stretch. It's impossible to extract trend lines from that hodgepodge. Another problem with collections: compilers are naturally drawn to the vivid, artistic, and prominent. Why reproduce that little black-and-white woodcut, from an ad one column wide, and all in agate type, when you can reproduce that lavishly engraved ad with color touches, that occupies the entire back cover, and gives just as much of a period feel? Problem: 117 of the 220 ads in that issue of 1898 may have been just like that unimpressive 
little woodcut; another 100 were a little bigger and nicer, but not by much; and the back cover ad was the only full-page, fully engraved, partially colored ad in the entire issue. You can't do history if someone else has filtered your sample of ads according to criteria unknown.

Last, there is a subtle problem with drawing continuous samples of ads in volume. Marchand (1985) looked at 180,000 ads; probably every ad in the magazines he sampled. Accordingly, he could only look across 15 years or so, making it impossible for him to see which changes of that era were sustained. Likewise, when an author samples from every decade, a story of fad and fashion, or cyclic change, becomes probable; and the fewer the number of decades sampled, the less likely that trends will emerge. It was easier, for us, to see how ads from the 1950s differed from 1980s ads, because 30 years is a long time in advertising. If we had had to tell a story about 1950s ads versus 1960 s ads versus 1970 s ads, we don't know that such clear patterns would have emerged. And it was also easier for us to pinpoint what changed from 1950 to 1980 because we could compare ads from both periods to those from later, in the 2000s, and earlier, from the 1920 s.

Changes in branding practice are gradual. Sampling time periods separated by 25-30 years helps to make changes visible. From the standpoint of the individual human beings who laid out these ads, by means of these intervals we skip ahead about one generation each time. Although hidden from us (unlike the authors of books, the creators of ads do not sign their work) in each period we are discussing a new population of creators, new persons inhabiting a new generation raised under new circumstances, but confronting the same challenge: how to brand.

At the beginning of the twentieth century, many magazine ads were indistinguishable from newspaper ads: printed in black and white, rather than color; consisting mostly of text, including price; and occupying a column, rather than the whole page. Color was not absent, but rare: only the ads on the inside and back of the cover pages, which were printed on a thicker, glossier paper stock, may have been color; and this opportunity was not purchased every issue. Full-page ads, while also not absent, were similarly the exception: excluding the covers, there may only be $3-4$ fullpage ads in an 84-page issue of $L H J$, but more than 100 column-length or fractional-column ads (December 1907). In our September 9, 1905 copy of the Saturday Evening Post (SEP), there is only one full-page ad, on the back cover; and it is the only ad with color.

The proportion of editorial material to advertising was still high around 1900. The short stories and self-help articles in $L H J$ filled a very large page -11 inches by 16 inches - with what today would be called fine print: 9-, 8-or even 6-point typeface. To the modern eye, each issue of $L H J$ is stuffed with a textbook's worth of words, crowded with print. We see few visual elements anywhere, and these are rudimentary and small. 
In the 1920s, everything exploded. Full-page ads in color became common rather than rare, distributed throughout the magazine rather than limited to the covers. The count of pages grew. A mid-decade issue of $L H J$ may have 200 or more pages in total, with dozens of full-page ads in color scattered throughout. The range of products advertised broadened: automobile ads proliferated, along with household appliances. The balance of pictures and words changed, both in the editorial matter and in the advertisements. To the modern eye, an $L H J$ from the 1920s remains print-heavy and wordy, especially in the advertisements; but visual elements, which had occupied 10 percent or even less of a typical page 20 years earlier, may now make up 20 percent, 50 percent or even more of some ads. White space appears in ads; layouts may (sometimes) be less crowded.

A typical 1920s ad will still appear old and dated to the contemporary viewer, primarily because the visual elements are mostly painted and drawn. Color photography for mass reproduction was not yet technically or economically feasible. Black and white photographs do appear in some ads, but illustrations, color or no, dominate.

Skipping ahead to the 1950s, the preceding depression and war years saw many changes in printing technology and its economics. Like the 1920s, the 1950s were an exuberant period of affluence, in which both consumer spending power, and the supply of things on which to spend, greatly expanded. As in the 1920s, magazines became thick again, and thick with ads. An LHJ issue may be 100-200 pages; a Better Homes and Gardens (BHG), or Good Housekeeping $(G H)$, may contain 200 or even 300 pages, many devoted to advertising.

Color photographs begin to replace illustrations in the 1950s. Illustrations continued to be common; color photography would not dominate until later. Black and white ads also remained common. New in the 1950s was the frequent use of color text: headlines ceased to be black print only. Early in the decade, advertisers threw all kinds of color onto the page: the headline was put in red, a subhead in green, a diagram in blue. To the modern eye, the use of color appears noisy and undisciplined.

The indiscipline extended to layout in the narrow sense. Advertisers routinely had a full page with which to work, even two pages, and they threw in everything but the kitchen sink. These continued to be large pages by current standards; no longer 11 by 16 inches, but still 10 by 13 inches or so, rather than the 8 by 10 size that had dominated since the 1980s. A 1950 s ad might include a close-up color photo, of the sort that would dominate later ads, but here that photo may be but one among half a dozen components. It may be accompanied by a diagram of how the product works, another picture with callouts of key features, another picture of the product in use, a package shot, or any number of things. There would still be hundreds 
of words of copy, a dozen subheads in three contrasting colors, and more. Layout tended toward the busy and cluttered.

A new element coalesced by the 1950s: the brand block. A brand block is a region of the ad page, typically at the bottom, reserved for brand identification. The brand block contains visual elements that appear across ads, as opposed to the remainder of the execution, which varies with each ad. Over time, the brand block grew more and more organized, and would become the primary means by which the advertiser self-identifies, declaring this ad message to be from this brand, this source, this entity whom you already know, and about whom you know a good bit from past encounters.

Earlier, in the 1920s, brand promotion had been more hit or miss. The brand name might or might not be rendered in a distinctive typeface. Even then, another iteration of the name, or maybe only that of the corporate owner, might be reproduced nearby in an ordinary or regular typeface, with a mailing address. As the brand block coalesced in the 1950s, advertisers exerted more control over how and where the brand was represented on the page. Logos - distinctive graphic elements that accompany or adorn the brand name - were also more likely to appear. However, by later standards, there was still not a lot of consistency in the presentation of the brand.

Moving forward, ads from the 1980s are of special note: during this decade any scholar older than 50 is likely to have acquired their tacit understanding of how an ad is supposed to look. ${ }^{15}$ These 1980 s ads would have dominated their consciousness when, as a student, an interest in pursuing advertising scholarship first took root. We mention this anchoring in the 1980s because of the danger that a psychologist - or any nonhistorically inclined person - will hypostatize the visual presentation of brands in advertising typical of the 1980s. The familiar gets misinterpreted as fundamental; temporary and era-specific features are treated as underlying structures that endure. We hope to break this pernicious habit. Ads from the 1980s are visually distinct from those that came before and after; the branding practices seen in the 1980s are not universal templates, but historically situated conjunctures.

If you put ads from the 1950s side by side with ads from the 1980s, you might conclude that advertisers had cleaned up their act. No longer do we see everything but the kitchen sink. In the prototypical 1980s ad, the visual portion of the ad has cohered into a single, large color photograph that may occupy half the page or more. We do mean occupy: the photo now fills the entire width of its part of the page. Below (and/or above) the picture is a text block or two. The headline, in large type, occupies a band above or below the picture; the body copy occupies another band, either directly beneath the headline, or with the picture sandwiched between. At the bottom, or in the bottom right corner, is a separate brand block 
containing the name in a large and characteristic typeface, the logo (if the brand has one, which many now do), and maybe a tagline, present across ad executions and sustained for some time. In many ads from the early 1980 s, ad layouts are this schematic. Ads contain a small number of discrete elements - picture, headline, text, brand - each filling a separate region, often a horizontal band that extends across the page.

The 1980s are also the era of the bold-faced, large font headline; or better, the double-bolded extra-large mega-type headline, with letter strokes thick as a pinky finger. There's nothing artsy about the typeface in these headlines, and advertisers don't bother to color or embroider the typeface of the headline. The prototypical headline uses a plain san-serif typeface, prints as pitch black, and shouts as loud as silent print can. With the clutter of the 1950s cleared away, and with MBAs trained in management science now acquiring decision-making roles, in the 1980s advertisers honed in on the specific tasks the print ad layout was to accomplish. Catch the eye with a big color picture. Shout the claim in the headline. Identify the brand.

The characteristic 1980s layout has been naturalized in subsequent psychological treatments. But there is nothing natural or permanent about it. You have to put ads from the 2000s side by side with ads from the 1980 s to break the spell. The 1980s layout, consisting of separate blocks of picture, text, and brand, was a temporary set of conventions. Not natural. Not permanent.

What happened to the 1980s layout? Photoshop happened. Computer graphics capability exploded in the later 1980s and early 1990s. The ability to create visual effects on a printed surface expanded far beyond what a photographer could accomplish in the darkroom by skillful airbrushing or superimposition. Also, the ability to design distinctive typefaces cheaply and quickly, and to lay them out easily, and to print them for no extra cost, expanded apace.

Two other technological developments were influential. If you can, get hold of a women's magazine from the early 1980s - neither black and white reproductions nor microfilm will do, it has to be the physical magazine and find a cosmetics ad with a large color photo of a model (the norm in ads for cosmetics, then, now, and for some time before). Look closely at the skin, and at the flesh tone. It's not right. It doesn't look real to the contemporary eye. The 1980 s ad attempts a photorealistic style that falls short of that goal. Next, repeat the exercise with a cosmetics ad published after 2005 . The flesh tone will be beautifully rendered. The ad photo could be a clear glass window onto a real model: a girl born with an outstanding complexion, further groomed by the expert application of cosmetics, and improved further by judicious Photoshop treatment, but a real-looking girl nonetheless. ${ }^{16}$ 
This exercise suggests that knowledge of the chemistry of inks and paper coatings, and the technology of image transfer, measurably improved over the intervening decades. There may also have been changes in the technology of camera lens manufacture or studio lighting. The technological details need not detain the rhetorician, but we must reiterate that the means of production, when it comes to printing images, continued to evolve following the 1980s. It may still be evolving today. The rhetorician wants to ask: what might be the effects of surpassing that threshold, that point where photorealism achieves its apotheosis? What might advertisers choose to do with pictures, once these can be made to look really, really, real?

The second technological development was the diffusion of the internet among ordinary consumers, beginning about the mid-1990s, along with the diffusion of screens: electronic surfaces for viewing images. By the mid-2000s, consumers were acclimated to high-resolution LCD screens, displaying full-color images pulled from the vast repository of the web. At about the same time, high-definition television took off, further increasing consumers' exposure to high-quality, photo-realistic images, but also to fictive, fantastic images, whether produced from hand-drawn animations, or as computer-generated visual effects. If we could count exposures per day to vivid high-resolution color imagery, among ordinary consumers, from 1950 to 2015, the curve would be exponential in some periods; and if we looked at the cost to deliver a color image to a mass audience, weighted by its photo-realism, we would see an exponential fall-off in that cost.

By the 2000s, the day-to-day existence of American consumers had become perfused by images. Under this deluge, printed magazine ads changed their layout exactly as you might expect. Pictures increasingly crowded out words. Pictures took over the entire ad. Words that remained were inscribed on the picture, rather than occupying a separate block beside or below the picture. Headlines stopped shouting; these reduced in size, often ceased to be bold black, and now graced the picture: they became captions rather than shout-outs.

The content of the pictures changed as well. Excepting cosmetic ads, which continue, as before, to feature photorealistic close-ups of face, hair, or lips, pictures are more likely to be visual effects, forged in software, rather than photos captured by a camera. Fictive and fantastic imagery has grown more common. Rhetorical devices of all kinds migrate to the picture: metaphor, personification, puns, hyperbole. In a word, images replace photographs in ads.

One final development, sociocultural rather than technological, helps to explain contemporary branding practice in print. From the 1950s, consumers' daily exposure to ads grew and grew and grew, waning a bit 
during recessions, but always rebounding. That may be why the bold screaming headlines seen in 1980s ads gradually disappeared. Thirty years ago, shouting in print might have served a branding purpose, have worked, been effective. But by the 2000s, consumers had become ever better at tuning out unwanted ad messages, especially the comparatively pallid messages of which print is capable (compare television, or web animations). A print ad that stooped to shouting was that much more easily spotted and screened out. Alluring pictures, beautiful and strange, now had better odds of stopping the consumer. Seduction, not command, became the preferred approach.

Now skip ahead to the 2030s. We can't, of course, at least not in this edition; the future hasn't happened yet. The point of this tease: it is unlikely that print advertising has ceased to evolve, has somehow reached a final state in which currently visible rhetorical strategies become fixed, to endure until advertisers cease to print on paper. On the contrary, we expect change to continue. Technological change has not ceased. The first generation of graphic designers to train on and use Photoshop throughout their careers is beginning to pass the mantle to a new generation. This next generation of advertising creatives, now moving into the mainstream of their careers and rising up the ranks, is the first to have grown up from birth inundated with web imagery; but they did not encounter the iPhone, and the explosion of mobile imagery, until late in their teens. The generation that grew up glued to a smartphone screen isn't in college yet, much less employed. Change will continue.

In the next chapter we introduce and discuss examples from each of the five eras briefly canvassed above. In capturing visual branding practice, words take us only so far. 